\title{
África Subsahariana Contemporánea: andadura, prejuicios y consecuencias de su situación en la valoración de sus ciudadanos
}

\section{Contemporary Sub-Saharan Africa: journey, prejudices and consequences of their position in the valuation of its citizens}

Lito Nunes Fernandes Doutorando em Economia (Universidade Federal do Rio Grande do Sul - UFRGS) Professor da Universidade Colinas de Boe. linufeppge07@yahoo.com.br

\begin{abstract}
Resumen
La difícil situación socioeconómica que enfrentan los países del África Subsahariana es resultado de muchos factores adversos por los que este continente pasó a lo largo de su historia. Este artículo pretende traer de forma breve, el recorrido de África Subsahariana hasta sumergirse en la actual situación. Así, el objetivo del mismo es demostrar que los impactos de la colonización, la esclavitud, neo-colonización y la actual desigual globalización, son los principales causadores de la problemática africana.
\end{abstract}

Palabras-chave: África subsahariana. Colonización. Esclavitud. Pobreza. Occidente.

\begin{abstract}
The socioeconomic situation facing the countries of sub-Saharan Africa is well known, due to a whole series of events that crossed the continent throughout its history. In this direction, he explains how it actually started the process of slavery in Africa as well as demonstrate the true reason why the region traversed by the dive in this situation. The purpose of this study is to demonstrate that the impacts of colonization, slavery and neo-colonization, were the main causes of the problems of sub-Saharan Africa.
\end{abstract}

Key words: Sub-Saharan Africa. Colonization. Slavery. Poverty. Western.

Originais recebidos em: 30/12/2010

Aceito para publicação em: 27/01/2011

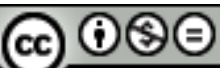

(cc) EY No No Este trabalho está licenciado sob uma Licença Creative Commons AtribuiçãoUso Não-Comercial-Vedada a criação de obras derivadas 3.0 Unported License. 


\section{Introducción}

La historia de África subsahariana, es una historia de repetición de ciclos de dependencia, lo que además de provocar efectos negativos en su desarrollo, permite que gran parte de su población enfrente situación de pobreza y miseria. Sin embargo, este triste episodio es aprovechado por algunos "escritores" para hacer bromas y cuentos sin racionalidad en el momento de narrar la historia subsahariana, ignorando por completo que en realidad, la actual situación por la cual atraviesan estos países fue provocada por las grandes potencias occidentales.

Según Ki-Zerbo (2010), la inmensa riqueza cultural, simbólica y tecnológica substraída da África para el continente americano, creyó condiciones para el desarrollo de sociedades donde elementos europeos, africanos, de las poblaciones originarias y posteriormente, de otras regiones del mundo, convivan de manera distinta y compleja. Para este mismo autor, solo recientemente están siendo reconocidos la labor que los negros africanos desempeñaron en la formación de las sociedades del continente americano. Sin embargo, esa comprensión todavía esta restricta a los altos estudios académicos y son pocas las fuentes de acceso público para evaluar ese complejo, considerando inclusive el ponto de vista del continente africano.

Indudablemente, la historia del África subsahariana'(ASS en delante) es totalmente desconocida o ignorada siendo que muchas veces es contada con prejuicios y desinterés (Filho, 2000). Durante siglos, los países subsaharianos hicieron resistencia tenaz a la ocupación extranjera de su territorio, y muchos elementos de la investigación histórica permiten afirmar que numerosas formaciones sociales y políticas en ASS habían alcanzado un notable y desarrollado nivel de estado de derecho y de gobierno, o sea, ASS tenía un avanzo substancial antes de la llegada de la colonización europea. Inclusive, durante los imperios africanos, existían reglamentaciones, órdenes y normas aceptadas por todos.

La ironía y el desprecio con que algunos autores occidentales describen la situación de los países subsaharianos son enormes e inaceptables. En este sentido, Vizentini (1998) argumenta que el conocimiento de la realidad africana, y más

\footnotetext{
${ }^{1}$ África Subsahariana, también conocida como África negra, aunque muchos consideran esta expresión políticamente incorrecta u ofensiva, corresponde la región del continente africano al sur del Desierto de Sahara. La palabra subsahariana se deriva de la convención euro-centrista, según el cual el norte "arriba" y el sur "abajo" (de allí el prefijo sub) (Fernandes, 2008). O sea, son países que no hacen parte de África del Norte o Magreb.
}

Em Debat: Rev. Dig., ISSNe 1980-3532, Florianópolis, n. 5, p. 16-33, 2011. 
particularmente de la historia de ASS constituye un grave e inaceptable vacío en la enseñanza de la sociedad occidental.

El tamaño de esta ignorancia incluye el propio uso de la expresión África o africano, donde se escuchan expresiones absurdas e ignorantes como: quiero conocer África, tengo un amigo africano, como es allá en África etc., como si estuviesen refiriendo a un país y no a un continente. El grado paranoico del caso, no es que las personas que ironizan con este asunto sean de bajo nivel cultural, al contrario, son intelectuales, científicos, profesores, alumnos universitarios y sobretodo, trabajadores de los más conceptuados medios de comunicación. Esa cuestión, induce pensar si en realidad no saben o lo dicen por otra connotación caprichosa.

La colonización impuesta a ASS delimitó fronteras que muchas de las veces correspondían a unas simples líneas imaginarias, permitiendo injustamente la clasificación como extranjeros a pueblos y comunidades que son perfectamente idénticas. A raíz de esta situación, surge la noción de etnia o el fenómeno de la etnogénesis, permitiendo que los conflictos desde el siglo XIX, ubicasen sucesivamente en tres conceptos o realidades: (i) nación, con las guerras de resistencia frente a la conquista colonial y los movimientos de liberación nacional, (ii) los conflictos interafricanos después de las independencias y (iii) los conflictos que se interiorizan cada vez más en la actualidad, siendo las Guerras Civiles y los Golpes de Estados sus expresiones más llamativas (Ki-Zerbo, 2002).

Independientemente de todos estos factores, los datos del Fondo Monetario Internacional y del Banco Mundial, demuestran que en los últimos años los países subsaharianos venían creciendo inclusive más que la media mundial, con un PIB estabilizado alrededor de 5\% al año, muy cerca de los mágicos 7\% considerados por especialistas como fundamental para sacar el ASS de la pobreza. Infelizmente, la crisis financiera internacional vino a interrumpir esa dinámica de crecimiento; aunque, al igual que el resto del mundo, algunos de países subsaharianos están superando con gran capacidad las consequências negativas de las crisis. Sin embargo, estos datos publicados por los organismos internacionales son ignorados por académicos y demás llamados "investigadores científicos" en el momento de abordar las cuestiones del desarrollo de ASS. En cambio, se limitan a relatar y demostrar solamente los datos desactualizados e imágenes estáticas de ASS de décadas anteriores o inclusive los archivos de la entonces época de colonización. 
El objetivo de este trabajo es demostrar algunos equívocos de académicos, medios de comunicación y demás medios especializados en la hora de abordar la problemática subsahariana, bien como relatar cómo y por qué ASS arribó a la situación donde se encuentra en la actualidad, partiendo de la hipótesis de que la esclavitud, colonización y neo-colonización constituyen las principales causas.

En este sentido, independientemente de esta introducción, el trabajo está dividido en otras cinco partes. La segunda parte presenta los aspectos históricos de ASS. La tercera parte presenta una breve visión de la esclavización desde la perspectiva subsahariana. En la cuarta parte, son relatados las consecuencias y el impacto de esta problemática en la valoración de ASS en general y de sus ciudadanos, en particular. La quinta parte esboza un longo caminar del origen de la actual situación de la región en análisis. En la sexta parte son presentadas las consideraciones finales y por ultimo las bibliografías.

Figura 1. Países de África Subsahariana

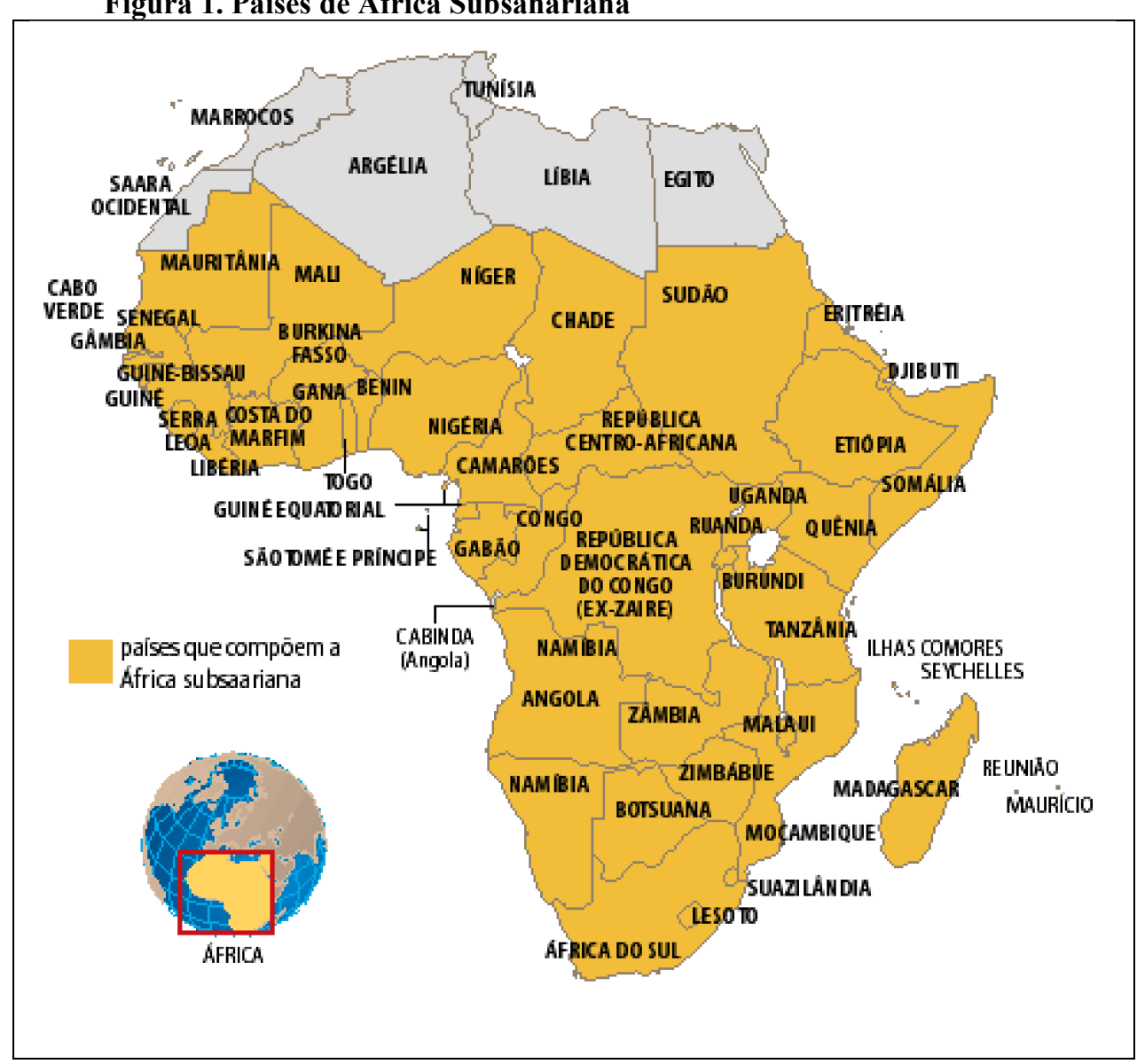

Fuente: imágenes de Folha.com (2010) 


\section{Algunas consideraciones sobre África Subsahariana}

África subsahariana como se puede ver en la Figura 1, está conformada por grandes países en volumen de población como Nigeria con 150000000 millones de habitantes y otros pequeños como Cabo-Verde con tan solo 500000 mil habitantes ${ }^{2}$. La mayoría de los países de esta región enfrentan problemas de diversas índoles: escasez de infraestructura, pobreza crónica generalizada, alto índice de analfabetismo (Fernandes, 2008). El índice de crecimiento demográfico de ASS es la más elevada del mundo, y aproximadamente la mitad de los refugiados registrados en las Naciones Unidas, es oriunda de esta región. Los peritos internacionales constataron que hace ya muchos años atrás, el crecimiento de la población subsahariana ultrapasa el de su producción, y esa tendencia puede venir a mantenerse, a no ser que sean tomadas medidas necesarias y eficientes.

La auto-suficiencia alimentaria en la región no está asegurada, además, la esperanza de vida, el estado sanitario de la población, la mortalidad infantil junto a la tasa de alfabetización y el nivel de formación tecnológico son las más frágiles del mundo (Zoctizoum, 2006). Según el mismo autor, en el plano económico, la fragilidad original llevó a una expansión desigual del sector público teniendo en cuenta que la mayoría de los sus gobiernos no contaban y otros aún no cuentan con recursos humanos capaces de asignar de forma equitativa los pocos recursos disponibles. Este factor, unido con la falta de experiencia de empresas públicas y las fragilidades autóctonas en casi todos los sectores incrementan aún más la dependencia económica subsahariana respecto al exterior, llevando constantemente a sus gobiernos a contraer préstamos con elevado interés para resolver algunos problemas.

En este sentido, se puede decir que la administración del Estado en los países de ASS se vuelve cada vez más difícil teniendo en cuenta el carácter embrionario de los servicios aduaneros y fiscales debido a la ausencia de previsiones económicas, programación presupuestaria y financiera, planificación global, exceptuando algunas experiencias.

\footnotetext{
${ }^{2}$ Los países que componen ASS son los siguiente por orden alfabética: Angola, Benín, Botsuana, Burkina Faso, Burundi, Cabo-Verde, Camerún, Chad, Congo, Costa de Marfim, Eritrea, Etiopía, Gabón, Gambia, Gana, Guinea- Conakry, Guinea-Ecuatorial, Guinea-Bissau, Kenia, Islas Comores, Lesoto, Liberia, Madagascar, Malawi, Mali, Mauricia, Mozambique, Namibia, Níger, Nigeria, República Democrática del Congo, Republica Centro-Africana, Ruanda, São Tomé y Príncipe, Senegal, Sierra Leona, Seychelles, Somalia, Suazilandia, Sudan, Sudáfrica, Tanzania, Togo, Uganda, Yibuti, Zambia, Zimbabue.
} 
En relación a la cuestión de la deuda externa, la situación de la región es dramática. En 1996, el FMI y el BM aprobaron con el apoyo de G-7, los términos de la iniciativa de la deuda externa para 41 Países Pobres Altamente Endeudados (PPAE) con el objetivo de alcanzar unos niveles de deuda sostenible con el fin de estimular el crecimiento económico y la reducción de la pobreza (Gemma y Colon, 2003). Según los mismos autores, los requisitos para que un país (como la mayoría de ASS) pueda acceder a la iniciativa, es decir, aquellos para que sea considerado como país elegible, son altamente restrictivos, quedando limitada esta oportunidad a un conjunto de países pobres, muy endeudados y marginalizados de los flujos financieros internacionales de capital. ¿Que les cuesta a los países desarrollados perdonar por completo la deuda externa los países ASS si durante siglos, fueron ellos mismos que saquearon toda la riqueza que ASS tenia? Así, la gran pregunta aquí es: ¿quién tiene que pagar a quien?

Los fondos que algunos países de ASS destinan al pagamiento de la deuda llegan a alcanzar el $70 \%$ de su PIB, y si estos países se obtuviesen el perdón total de sus deudas, sus deplorables situaciones podrían mejorar, ya que ese fondo iba ser revertido en programas sociales como educación, salud y otros sectores. Aún así, muchas veces los expertos internacionales, sobretodo los del Banco Mundial y del Fondo Monetario Internacional, no son justos en sus raciocinios y casi nunca hacen un análisis realista de la verdadera causa del problema subsahariano.

Para Toussaint y Millet (2006), estos “peritos internacionales", sentaditos desde sus mansiones en Washington, Paris o Londres, se limitan a tomar los efectos por causas y ocultan o dejan de reconocer que la dominación del continente durante siglos aún constituye la causa de las deudas y el verdadero obstáculo al desarrollo subsahariano. Las exportaciones de fuerzas vivas desorganizaron las economías de ASS y rompieron con la continuidad histórica y su capacidad de adaptación a nuevas situaciones (Filho, 2000). A este hecho, se le suma la repartición de África entre las grandes potencias europeas a partir de la Conferencia de Berlín ${ }^{3}$. Como consecuencia, los países africanos se quedaron impedidos de desarrollar ya que sus tierras pasaron al poderío de los extranjeros (Cardoso y otros, 2009).

\footnotetext{
${ }^{3}$ La Conferencia de Berlín, también conocido como scramble of Africa (corrida para África) fue realizado entre el 19 de Noviembre de 1884 a 26 de Febrero de 1885, a petición de Portugal y organizada por el canciller alemán Otto Von Bismarck, donde aparte de Portugal y Alemania, también participaron Inglaterra, Francia, España, Italia, Bélgica, Holanda, Dinamarca, EUA, Suecia, Austria, Hungría, Turquía. En el evento, las grandes potencias occidentales decidieron dividir África en sus áreas de influencia, no respetando las reglas, ni la historia y relaciones étnicas entre los países; hecho que se quedó conocido como Imperialismo o Nuevo Colonialismo.
} 
La actual delimitación de las fronteras que corresponde a un largo proceso que inició con el comercio de esclavos tanto por la parte de los árabes como por los europeos y luego por la colonización siguiente, así como las dinámicas imperialistas inter-africanas, ha sido la causa de numerosas consecuencias negativas. La misma delimitación oriunda de la dichosa Conferencia de Berlín ha permitido el desplazamiento de las etnias africanas, una mayor fragmentación en varias ciudadanías de pueblos que en realidad eran solidariamente unidos no por lazos políticos, pero por la lengua y cultura.

Gran parte de los países subsaharianos fueron privados de sus capacidades de organización económica, pero en la actualidad, muchos autores ignoran u olvidan ese detalle. ¿En realidad, por qué estos factores son ignorados por los especialistas o científicos que escriben sobre la temática subsahariana? Resulta mucho más fácil arrojar la culpa a los gobiernos subsaharianos por mala administración o existencia de corrupción, y de esta forma excluir a las grandes potencias occidentales de sus responsabilidad en esta problemática. Como si eso no bastase, los señores occidentales, alegan que la única vía para que los países subsaharianos resuelvan sus problemática, es liberalizar sus economías, permitiendo la entrada de las grandes multinacionales extranjeras (Toussaint y Millet, 2006).

O sea, es innegable que fue orquestado un plan por parte del occidente de despojar las riquezas de ASS y transferirlas a lo largo de la historia de la ocupación colonial para los países occidentales. Además, para nadie es un secreto que ningún país occidental quiere el desarrollo de ASS porque si esto llegara a suceder: ¿donde continuarían extrayendo las materias primas?, ¿dónde irían conseguir mano-de-obra barata? o ¿dónde sus industrias farmacéuticas irían hacer sus experimentos?

Gracias a ese dominio, muchos experimentos de industrias occidentales son hechos en los países subsaharianos, teniendo en cuenta que sus dirigentes son manipulados con las hipócritas políticas occidentales de simular que son trabajos de organismos internacionales, para poder testar en seres humanos, experimentos científicos y otros productos que en condiciones normales deberían ser testados en los animales.

\section{Una mirada subsahariana sobre la esclavitud}


En la historia de la humanidad, la posición que África y en particular ASS ocupaba antes de la invasión europea era muy privilegiada. La llegada de los europeos no solo marcó el inicio de los contactos entre la civilización europea y africana, sino que también significó la destrucción de las sociedades autóctonas que habían creado instituciones propias y que funcionaban con cierta estabilidad. Al mismo tiempo, también significó la intensificación de la nefasta actividad de esclavización que agotó el África de brazos y mentes por casi cinco siglos (Filho, 2000).

En los libros que narran la historia, o artículos que hablan sobre la esclavización, se nota que son historias inventadas y narradas con el único objetivo de demostrar la superioridad occidental sobre la africana. Son escritas que narran con todo orgullo la cuestión de la esclavización, donde presentan imágenes de subsaharianos esclavizados encadenados, colocados en los diversos buques y embarcaciones sin las mínimas condiciones humanas. En realidad, la historia narrada en estas literaturas no explica detalladamente el origen de la cuestión de tráfico de esclavos o intercambio de trabajadores, término utilizado por los entonces reyes e imperadores africanos.

Es bueno no olvidarse que antes de la llegada Europea, ASS mediante sus diversos imperios, reinos y dinastías contaba con instituciones bien organizadas y estructuradas. Además, los diversos imperios y reinados, tenían personas que trabajaban para la casa real ${ }^{4}$. Estos trabajadores cuidaban las plantaciones o las haciendas y otros desempañaban las funciones de guardias personales de los reyes o cuidadores de los hijos de estos. Paulatinamente, muchos de estos trabajadores fueron siendo aceptados e incorporados a la propia casa real por diversos motivos. Algunos por sus fidelidades ante los amos, y otros mediante historias de amor, ya que en muchos casos las hijas de los reyes se enamoraron de algunos trabajadores de la casa o algunos hijos de los reyes se enamoraron de las empleadas.

Cuando llegaron los colonizadores europeos y vieron como la organización de los imperios funcionaba, viendo que los reyes o imperadores tenían trabajadores a su disposición realizando varias tareas, también dijeron a los reyes africanos que pretendían llevar algunos de los trabajadores para Europa para que estos desarrollasen semejantes funciones. Fue a partir de este episodio, que comenzó el verdadero

\footnotetext{
4 Incluso ciudadanos europeos, aunque difícilmente estos relatos son encontrados en las escritas occidentales, ni mucho menos reconocer que también fueron colonizados por los africanos.
}

Em Debat: Rev. Dig., ISSNe 1980-3532, Florianópolis, n. 5, p. 16-33, 2011. 
intercambio de trabajadores - expresión mundialmente conocida como "esclavitud" en terminología occidental.

Los reyes subsaharianos no veían ningún impedimento en la petición hecha por los colonizadores y en este sentido, cedieron algunos de sus trabajadores, recibiendo en cambio, tabacos, armamentos y otras mercancías europeas; pensando que sus trabajadores irían realizar las mismas funciones que hacían en sus países de procedencia. O sea, no tenían conocimiento que los trabajadores eran maltratados, castigados, esclavizados cuando llegaban a Europa y, sobretodo en las Américas, motivo por la cual la esclavitud ha durado mucho tiempo, ya que cuando los europeos volvían para ASS, decían a los reyes que todo estaba bien con los trabajadores. Así, los reyes hacían más y más intercambios de trabajadores con los europeos.

Era obvio que si los reyes supieran que sus trabajadores iban a ser esclavizados, maltratados y obligados a trabajos forzosos, seguramente iban a detener inmediatamente esta relación. Además, en ese entonces, no existían medios de comunicación como ahora, ni vías para que los reyes y el pueblo subsahariano en general, tuviesen informaciones de sus parientes. Así, en el medio de la sociedad subsahariana prevalecía la vaga idea de que los trabajadores eran enviados para otros países, para trabajar honestamente con vista a mejorar sus condiciones de vida. Lo mismo, se puede relacionar con lo que sucede en la actualidad, donde trabajadores de varios países subdesarrollados inmigran para Europa o América del Norte en busca de mejorar las condiciones de vida.

Sin embargo, algunos libros, artículos escritos por autores no africanos, destiñan totalmente esa historia y la narran como se los reyes tuviesen una verdadera noción de lo que estaba pasando. La verdad es que el intercambio de trabajadores existía entre subsaharianos y árabes mucho antes de la llegada de los europeos, razón por la cual se pensó que sería el mismo proceso con los europeos. Pero, el cinismo y la hipocresía europea prevalecieron sobre la buena voluntad y sentido común de los reyes africanos; y estos sin el mínimo conocimiento permitieron esclavizar su pueblo de manera cruel e inhumana, historia que hoy algunos no nativos en el África, narran con mucho orgullo.

Finalmente, hay un punto llamativo e interesante que no merece pasar de alto: la Iglesia Católica Apostólica Romana y española se posicionaron a favor de la esclavización de los africanos, y condenaba la esclavización de los indios ${ }^{5}$. Es obvio que

\footnotetext{
${ }^{5}$ Igualmente, la Iglesia Católica Apostólica Romana fue uno de los mecanismos usados por los colonizadores para dominar a los pueblos africanos, aprovechándose del respeto que los africanos tenían por Dios divino, ya que los responsables de la iglesia eran vistos como mensajeros de Dios.
} 
el porqué de esto, todos lo sabemos, pero cuando viene de una institución que supuestamente sigue los pasos de Dios creador, las cosas pintan muy feo para estos escolásticos. Este hecho demuestra que hasta la facción que supuestamente debería ser como mínimo imparcial, se posicionó a favor de las hipócritas ideologías racistas occidentales.

\section{Valoración de África y de los ciudadanos subsaharianos como consecuencias de esta problemática}

Toda esta problemática subsahariana que venimos relatando hasta el momento, hace que muchos vean a los países de ASS y, sobretodo a sus ciudadanos, de forma errónea y lleno de perjuicios. Esto lo podemos comprobar en el uso en el sentido peyorativo de la expresión África o africano referido anteriormente en la introducción del trabajo, o las imágenes de pobreza y miseria que siempre aparecen en la media y en los medios de comunicación internacional cuando se habla de ASS. Según Rollim (2009), existe una tendencia de tratar el agregado africano de forma conjunta, pero en realidad, es una estrategia cuyo objetivo es no dejar ver los avances que están siendo realizados por algunos países individualmente.

Lo más transcendental de este punto en análisis lo encontramos en la hora de valorar las diversas ciudadanías africanas. Por ejemplo, los ciudadanos de los países africanos, tanto estudiantes como inmigrantes, frecuentan las universidades, trabajan o juegan el futbol junto a los ciudadanos de otros continentes. Sin embargo, es costumbre dirigirse a los estudiantes o inmigrantes del continente americano como norteamericanos, argentinos, brasileños, chilenos, colombianos etc.; de los países europeos como alemanes, italianos, españoles, portugueses; de los países asiáticos como chinos, coreanos, japoneses etc. ¿Por qué entonces se dirigen a los estudiantes o inmigrantes de los países africanos como "africanos" y no como angolanos, congoleses, guineanos, kenianos, etíopes o senegaleses?

Dicho de otra manera ¿porque no se dirigen a los naturales de otros continentes como asiáticos, europeos o americanos, como se refieren a los africanos? Partiendo de un raciocinio lógico, la pregunta es: ¿en realidad es solo por ignorancia, desconocimiento o por detrás de ese hecho hay otra connotación? ¿Será que no conocen 
los nombres de los países africanos, la ciudadanía o sus nacionalidades? Supuestamente en el pleno siglo XXI con el desarrollo de las tecnologías, todos ya deberían saber que África es un continente como Europa, América, Asia y Oceanía o Australia.

Indudablemente, para analizar la actual situación de ASS, irremediablemente se debe retroceder un poco en el tiempo y revolver el antes y el después de la colonización, así como el período post-independencia. Así, cuando todos se actualicen hasta con el mínimo detalle los aspectos de la historia subsahariana y de África en general sin hipocresías, seguro que todos llegarían a única conclusión: la situación que estos países enfrentan en la actualidad es producto del dominio de siglos de colonización en donde fueran robados, expropiadas, explotados brutalmente y saqueadas cobardemente todas las riquezas y recursos que tenían durante más de 600 años (Fernandes, 2008).

\section{Travesía y origen de la actual situación subsahariana}

Según Zoctizoum (2006), para saber como exactamente el ASS llegó a la actual situación, hay que interrogar primeramente la historia. Tras la esclavitud, el dominio físico y la instauración del sistema colonial retardaron en casi un siglo la retomada de las instituciones y del desarrollo africano, oprimiendo, barbarizando y colonizando territorios y seres humanos, disminuyendo las coadyuvantes de su propia historia (Filho, 2000). Dicho de otra manera, ASS fue obligada a comprimir el papel de principal impulsor de la industrialización occidental. Sin embargo, estos factores que provocaron que los Estados subsaharianos atrasasen en ordenar sus economías y finanzas públicas, parecen ser ignorados por los académicos y científicos occidentales, que alegan la ausencia de la democracia, instituciones sólidas y políticas, infraestructuras y problemas étnicos como principales factores de la actual situación subsahariana.

La literatura occidental pasa por alto los verdaderos factores originarios de toda esta problemática como la dominación durante siglos, el proceso de colonización que ha venido posteriormente $\mathrm{y}$ el trato desigual en el comercio internacional. Otro factor relevante y cruel que permite hacer otra lectura de la dura realidad subsahariana es que durante la colonización era prohibida la industrialización y la escolarización en las colonias. De esta manera, es totalmente normal que existan altos índices de analfabetismo y escasez de infraestructura en el ASS. 
Las infraestructuras, la democracia y el desarrollo no pueden ser construidos en un período de 40 años $^{6}$. Paralelamente, resulta casi imposible erradicar el analfabetismo, si estos países solamente empezaron a tener universidad después de las independencias nacionales y, otros, inclusive solo tuvieron universidades en la década de 1990. En una visión más realista, es una crueldad exigir a los países subsaharianos de estar en el mismo nivel de desarrollo con los países de otras regiones.

Cuando terminó la Segunda Guerra Mundial los Estados Unidos destinó una cuantía exorbitante para la reconstrucción de la Europa destruida, llamado Plano Marshall. Partiéndose de este ángulo de visión, ASS que fue saqueada, destruida y robada todo lo que tenía construido a lo largo de casi cinco siglos: ¿por qué no se idealizó un plan para su reconstrucción? o ¿por qué no hubo sanciones a los países colonizadores por todo lo que hicieran en ASS?

En otro ámbito, después de las independencias nacionales los nuevos estados subsaharianos necesitaban de capital financiero para hacer nuevas infraestructuras, financiar las industrias y la construcción de las escuelas que eran prohibidas en la etapa colonial como ya referida anteriormente. En ese periodo, el mundo estaba inundando de liquidez y el volumen de dólares aumentaba considerablemente, y resolvieran prestar a los países africanos. Aprovechándose de la situación, algunos países industriales prestaban a los gobiernos africanos con intereses bajos, para que estos pudiesen comprar sus productos o mercancías en la misma proporción de la cantidad del préstamo, hecho que según Toussaint y Millet (2006), permitió el surgimiento de la parte multilateral da deuda externa.

Durante los primeros años de la independencia, los gobiernos y las élites subsaharianas endeudaron fuertemente a sus países, aprovechando para transferir a sus cuentas personales las cifras pedidas como préstamo en nombre del Estado. Ese era el motivo por el cual, muchos dictadores africanos poseían fortunas mayores que las deudas de los respectivos países. Como no podía ser diferente, esta situación también benefició a los bancos de los países desarrollados ya que el dinero volvía a sus cofres y podía ser prestado nuevamente a otros. O sea, los países desarrollados también fueran cómplices de la corrupción de los dictadores subsaharianos en la hora de dilapidar las fortunas de sus países y que tuvo una contribución decisiva en el aumento de la deuda (Toussaint y Millet, 2006).

\footnotetext{
${ }^{6}$ La mayoría de los países africanos consiguió la independencia en la década de 1960, o sea, actualmente es poco más de 40 años de independencia, período muy corto para evaluar el desarrollo de un país.
} 
Según Fernandes (2007), una de las iniciativas interesantes para el arranque del desarrollo en el África fue la elaboración del Plan de Acción de Lagos (PAL) ${ }^{7}$, que contenía puntos fundamentales para el desarrollo del continente de forma general. Entretanto, cuando el plan empezaba a dar sus primeros frutos y la retomada del crecimiento, apareció la dichosa política dictatorial del FMI/BM denominado Políticas de Ajuste Estructural- PAE, que en realidad, no solo ha venido destruir los avances que ASS estaba obteniendo a través del PAL, sino que también albergaba la intención de abrir las fronteras africanas y liberar sus economías para la entrada de las grandes transnacionales occidentales para así continuar a perpetuar la dependencia africana ante a las grandes potencias occidentales.

Sin lugar a dudas, el verdadero motivo de la implantación de los Programas de Ajuste Estructural (PAE) ${ }^{8}$, era la perpetuidad del sistema capitalista y la explotación en ASS. Estos programas que tienen como base las racionalidades internas y externas, en vez de mejorar los problemas del continente contribuyeron todavía más para empeorar la situación provocando entre muchos otros factores adversos, pobreza al influir negativamente en los aspectos del desarrollo humano y en el modo de vida de los más pobres.

Los resultados de la PAE estuvieron muy abajo de las expectativas, o sea, ha producido efectos perversos: la supresión de los déficits públicos nació no del aumento de renta, pero sí de la reducción o eliminación de los gastos sociales y de las inversiones públicas, la depreciación muchas veces conduce a mejoras en los términos de intercambio agrícola interno a favor de los cultivos de exportación y en detrimento del consumo local (Ki-Zerbo, 2002).

\footnotetext{
${ }^{7}$ El Plan de Acción de Lagos (PAL) fue fruto de varias negociaciones entre la Comisión Económica de las Naciones Unidas para África (ECA) y la Organización de la Unidad Africana (OUA). Así, en 1976, ECA presentó un plan revisado de los principios para la instauración de una Nueva Orden Económica Internacional para África, adoptado por la Conferencia de los jefes de Estados y Gobiernos en 1977. En 1979, hubo un Coloquio en Monrovia capital de Liberia, sobre las perspectivas del desarrollo económico africano y en el mismo año ECA y PNUD organizaron un seminario sobre modelos alternativos de desarrollo y el estilo de vida para África. Todas estas iniciativas concluyeron con la segunda sesión extraordinaria de los jefes de Estados y gobiernos reunidos entre el 28 e 29 de Abril de 1980 en Lagos (Nigeria), donde se elaboró un importante documento que contenía un Plan de Desarrollo africano denominado "Plan de Acción de Lagos", cuyos principales artífices fueron Adebayo Adedej y Edem Kodjo, con la colaboración fundamental de Michael B Kingue y Albert Tévoédjré. Ese plan direccionada a hacer un balance de los 20 años recorridos entre 1960, año en que la mayoría de los países africanos consiguieron sus independencia hasta 1980 para así delinear las estrategias para el perdió 1980 - 2000.

${ }^{8}$ De manera resumida, el fundamentalismo económico de los PAE se basa en los siguientes principios: (i) la eliminación de la función económica del Estado; (ii) las privatizaciones del mercado en todos los aspectos de la vida nacional; (iii) la máxima abertura externa, a través del fenómeno de las exportaciones y del tratamiento favorable a las inversiones extranjeras, conforme la exigencia de la economía mundial.
} 
En realidad, la implementación del PAE tenía otro motivo bien claro: alejar los países africanos de los ideales socialistas. En aquel entonces, se vivía el clima de la bipolaridad (Guerra Fría), y muchos países africanos después de la independencia tenían ciertas inclinaciones socialistas, por recibieren ayudas de la extinta Comunidad de Ayuda Mutua Económica (CAME). Para frenar esa tendencia en plena época de Guerra Fría, los EUA actuaran de forma estratégica, con implantación obligatoria de PAE que vino obstaculizar las ayudas que los africanos recibían del campo socialista.

Igualmente, los expertos y las agencias de cooperación occidentales para el desarrollo tienen por costumbre atribuir las causas del subdesarrollo en ASS a los factores tales como: la explosión demográfica, la falta de conocimientos científicos, la ausencia o escasez de espíritu empresarial, las condiciones naturales desfavorables, la falta de capitales nacionales, y el intervencionismo estatal. Según esa tesis, el desarrollo tenía que ser impulsado desde el exterior a través de la ayuda, la industrialización y la participación en el comercio internacional. En otro sentido de la palabra, argumentan que para alcanzar el desarrollo, los países subsaharianos tenían que seguir el modelo occidental de desarrollo o western way of live como referencia obligada, al margen de las realidades y especificidades africanas (Badi, 2002).

Para Badi (2002) el neocolonialismo liberal, basado en el presupuesto único de la política económica hegemónica en la cual prima lo material sobre lo humano para servir los privilegios de los ricos sobre los países pobres, consiste en reproducir el modelo occidental en ASS. Siendo así, el objetivo es la incorporación neocolonialista y total subordinación de ASS en el mercado mundial, con la complicidad de las élites locales. Frente a la incapacidad de identificar los objetivos, estrategias, obstáculos internos y externos rumbo al desarrollo, la élite subsahariana entregó la mayoría de sus pueblos a la orden neoliberal imperante y dominante, con graves consecuencias sociales, ambientales, políticas y económicas.

A nivel social, Badi (2002) insiste que la austeridad que los PAE imponen a los países subsaharianos va más allá del necesario y nunca en la restauración de los equilibrios económicos, además, que los mismos programas o políticas han reducido dramáticamente el poder adquisitivo provocando desempleos debido a despidos macizos de los funcionarios como consecuencias de las privatizaciones que aniquilaron los importantes progresos realizados en décadas anteriores, en los aspectos de la educación y salud. Todos estos factores provocaron aumentos de niveles de pobreza rural y urbana. 
Los PAE disminuyeron la capacidad de muchos subsaharianos pagar los servicios de salud, educación, sometidos a contribuciones de las familias empobrecidas ${ }^{9}$. Muchas escuelas, anteriormente subvencionadas por el Estado desaparecieron debido a cortes en los presupuestos consagrados a la educación, a través de despido de profesores y reducción de horas de clase y salario de los mismos; con la justificativa de reembolsar la deuda externa. Este es el factor explicativo para que las tasas promedia de matricula bajasen sensiblemente en ese período en comparación con la década de 1970, sobretodo en los países de baja renta provocando aumentos posteriores en la tasa de analfabetismo.

La abertura externa y el fenómeno de las exportaciones en la cual se fundamentan los PAE son responsables por el infarto ecológico actual del África, cuyo medio ambiente está totalmente desprotegido. Dicho de otra manera, el ASS destruye su medio ambiente unido al robo de los productos naturales por las multinacionales internacionales para pagar sus deudas y así satisfacer las necesidades occidentales. Las poblaciones de esta región destruyen el medio ambiente porque son pobres y necesitan cualquier recurso financiero para poder sobrevivir.

Las empresas transnacionales por su vez, aprovechan de su dominio tecnológico y de la no protección de los mercados subsaharianos, así como de los abundantes recursos naturales y la mano-de-obra barata, para desforestar con total impunidad y controlar el capital verde de farmacia vegetal, para las industrias medicas de sus respectivos países. Así, para Badi (2002) el hambre en ASS, no resulta de la falta de recursos, pero sí de la falta de su explotación, porque se exporta la producción en lugar de consumirla.

Una última reflexión nos permite seguir entendiendo la cuestión subsahariana. Por ejemplo, los hijos, nietos y sobrinos subsaharianos son pobres, porque sus padres son pobres y estos son pobres porque igualmente sus padres, abuelos y tatarabuelos también fueron pobres. O sea, no hubo ni podía haber ahorro familiar, no hubo ni hay herencia o transmisión de bienes como se verifica en otros continentes, no hubo acumulación de capital en ASS. Se sabe que la acumulación de capital y la obtención de lucros, son dos factores económicos claves en el proceso del crecimiento capitalista. Un

\footnotetext{
${ }^{9}$ Las recomendaciones del PAE presentan una clara contradicción. De un lado elimina la función económica y social del Estado, y por otra, pide que los Estados intervengan en la vida política para recortar las libertades y limitar el ejercicio del derecho, con vista a someter a la sociedad civil a ideología neoliberal. Así, su verdadero objetivo no es la restauración de una verdadera democracia, pero sí de "oligarquías liberales", encargadas de la aplicación del "pensamiento único" de la edificación de un Estado y un desarrollo burgués, o sea, convierte el Estado en instrumento de la globalización al mismo tiempo en que encarga al Estado la reconstrucción y control de la sociedad civil destruida por tal Globalización.
} 
proceso circular en la cual se acumula capital para aumentar el volumen de lucros y luego se invierte ese lucro para acumular capital y así por delante. Ahora bien, si los subsaharianos solo empezaron a dirigir sus países a partir de 1960, es prácticamente imposible hablar de la acumulación de capital ya que no eran dueños de sus tierras, de sus riquezas, de sus fuerzas de trabajo y sobretodo de la dirección de sus destinos.

Además, es sabido que el desarrollo tecnológico depende de la acumulación de capital, en la medida que el progreso técnico incorpore nuevos equipamientos e instalaciones, y que las propias investigaciones científicas dependen de grandes inversiones en capital fijo. Sin embargo, si te prohíben tener industrias, escuelas, universidades factores claves que a la postre te permitirán desarrollar y crear centros de investigaciones para I\&D como hicieron con los países subsahariano, no puedes desarrollar tecnología de punta, no puedes acumular capital, no puedes desarrollar. Así, la ausencia de acumulación de capital en ASS se suma a una larga y vasta lista de aspectos adversos por las cuales estos países enfrente la difícil situación en la actualidad.

\section{Consideraciones finales}

La historia de ASS, en vez de producir un efecto positivo en la opinión pública general, la verdad es que suscita un rechazo, burlas y discriminación. Es inconcebible, que en pleno siglo XXI, todavía haya gentes que siguen creyendo que África es un país e no un continente. En el prefacio del libro "História da África I: Metodologia e préhistória da África", Amadou Mahtar M'bow (Director general de la UNESCO de 1974-1987) argumenta que durante mucho tiempo, mitos y prejuicios de toda especie humana escondieron al mundo de la real historia de África. Para este autor, las sociedades africanas pasaban por sociedades que no podían tener historias, factor que condujo a que muchos autores no africanos alegasen que las sociedades subsaharianas no podían ser objeto de estudio científico, por falta de fuentes y documentos escritos.

Así, al escribir la historia de gran parte de de África, solamente se recorría a fuentes externas al continente africano, para así demostrar una visión no realista de la travesía de los pueblos subsaharianos, sino de lo que en realidad querían que sus lectores creyeran. Esto no da una idea de que se recusaba considerar el pueblo africano 
como creador de cultura original que florecieron y perpetuaron a través de siglos por vías que le son propias y que el historiador solamente puede aprender e narrar renunciando a ciertos prejuicios e métodos.

A fecha de hoy, lo mejor que estos dichosos escritores occidentales pueden hacer, es comenzar a contar la historia subsahariana como es realmente y no como vienen haciendo hasta ahora. Igualmente, los medios de comunicación, deben parar de manchar y denegrir la imagen de los países subsaharianos con archivos viejos y en desuso y muchas veces falsos, que relatan solamente pobreza y miseria, permitiendo cada vez más, un juzgamiento erróneo de ciudadanos subsaharianas.

Además, las políticas económicas occidentales en relación a ASS son falsas, hipócritas y con intención de sumergir todavía más el pueblo africano en la pobreza. La ideología neoliberal imposta a los países africanos a través de los PAE han profundizado más el subdesarrollo del continente y los sufrimientos humanos a los cuales han sometidos a una nueva forma del colonialismo, basada en la planificación privada globalizada.

Los países desarrollados disponen tecnología y recursos necesarios para permitir que el desarrollo sea alcanzado por todos y librar la humanidad de la pobreza y extrema miseria, así como medios para exterminar con los prejuicios bochornosos de sus ciudadanos. Sin embargo, esa voluntad no existe, en sentido de que con ASS desarrollada, los países desarrollados no tendrían donde apoderarse de las materias primas, donde abusar de mano-de-obra barata, donde vender sus arsenales bélicos, ni donde realizar sus experimentos científicos.

Finalmente, y aún reconociendo el gran peso de la ocupación extranjera en la situación actual de los países subsaharianos, la verdad es que también hubo una participación decisiva de los propios africanos. Esta participación africana comienza con los dictadores en las décadas pasadas que segaron todas las riquezas de sus pueblos hasta los actuales corruptos gobernantes, que próvidos de ideología capitalista, se dedican a maximizar sus riquezas en detrimento del resto de la población, inviabilizando el crecimiento y posterior desarrollo.

\section{Referências bibliográficas}

BADI, Mbuyi K. Neoliberalismo. África, septiembre, 2002. 
CARDOSO, K. F. et al. Erradicação da pobreza e da fome: desafios no contexto da crise mundial de alimentos. Simulação das Nações Unidas para Secundaristas- SINUS, 2009.

CÉSPEDES, Gemma; JAÉN, Artur. El alivio de la deuda en África. ¿Hacia la reducción de la pobreza?, ICE, tribuna de Economiza, enero-febrero, 2003.

FERNANDES, Joel. A Integração Econômica como Estratégia para o desenvolvimento econômico na África Ocidental. Dissertação apresentada na Universidade Federal de Santa Catarina. Florianópolis, Abril, 2007.

FERNANDES, L. Las Raíces Históricas del Atraso Económico en África Subsahariana. Textos de Economia. Florianópolis, v.11, n.1, p.11/38. Jan/jun, 2008.

FILHO, Pio. Integração Econômica no continente africano: ECOWAS e SADC. Cena internacional. Revista de Análise em Política internacional, Ano 2- №2, dezembro, 2000 .

KI-ZERBO, Joseph. História da África I: Metodologia e pré-história da África. Brasília: UNESCO, 2010.

- Gobernanza Mundial. El marco histórico de la gobernanza en África. Caravana: para un mundo responsable, plural y solidario, numero 6, agosto, 2000.

TOUSSAINT, Éric; MILLET, Damien. 50 Perguntas 50 Respostas sobre a divida, o FMI e o Banco Mundial. São Paulo: Boitempo Editorial, 2006.

ROLLIM, Cássio. O empobrecimento da África e as estratégias atuais para a reversão da situação. UFPR, Working Papers, n. 88, 2009.

VIZENTINI, P. A África e os estudos africanos: uma introdução. FAPA, Revista Ciências e Letras, nº 21, 1998.

ZOCTIZOUM, Yarisse. Histoire de la Centrafrique: Les diamants de la Trahision. Paris: Ed. Pharos, 2006. 